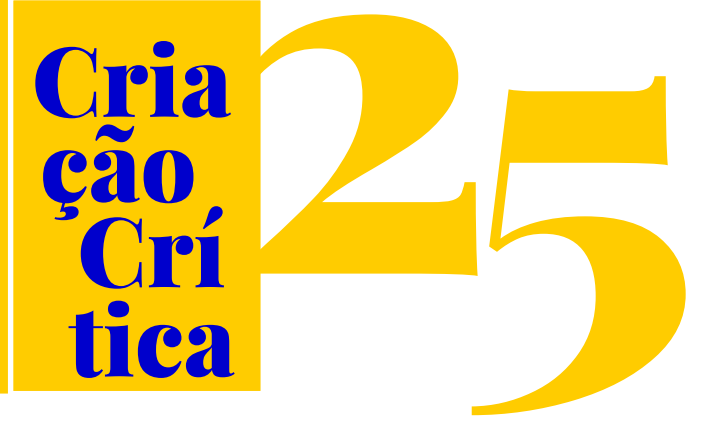

\title{
TRANSFICCIONALIDADE E CRÍTICA DE ARTE
}

André Soares Vieira ${ }^{1}$

RESUMO: Partindo do conceito de transficcionalidade proposto por Richard Saint-Gelais (2011), segundo o qual toda obra opera a partir da possibilidade de expansão da ficção, seja em forma de continuações (sequels), seja em forma de narrativas anteriores (prequels) à ficção apresentada, este trabalho focaliza o modo como Gonzaga Duque extrapola os limites da materialidade dos quadros, inserindo a ficção em descrições picturais de suas críticas de arte. Farei algumas reflexões acerca dos modos como o escritor e crítico de arte brasileiro descreve e narra de forma transficcional os quadros que comenta, valendo-se de uma linguagem a meio caminho entre a ficção e a crítica narrativa. Construídas em torno do referente, suas críticas de arte são elaboradas a partir do assunto da tela, remetendo, no entanto, a ações exteriores ao quadro. Trata-se de imaginar literariamente, seguindo os passos de Daunais (1997), as continuações do tema representado, evocando cenas não representadas, mas supostamente contidas na imagem, e sugerindo um outro tempo, anterior ou posterior, colocando espectador da pintura e leitor da crítica de arte diante de dois objetos culturais complementares, em que um é a medida do outro.

PALAVRAS-CHAVE: crítica de arte; Gonzaga Duque; literatura e pintura

\section{TRANSFICTIONALITY AND ART CRITICISM}

\begin{abstract}
From the concept of transfictionality proposed by Richard Saint-Gelais (2011), according to which all work operates from the possibility of expansion of fiction, whether in the form of sequels, or in the form of previous narratives (prequels) to the fiction presented, this work focuses on how some Gonzaga Duque art criticism extrapolate the limits of the materiality of the paintings, inserting fiction into their pictorial descriptions. In his search for a language midway between fiction and a critical narrative, I will make some reflections about the ways in which the Brazilian writer and art critic describes and narrates in a transfictional way the pictures he comments on. Built around the referent, his art criticim is elaborated from the subject of the screen, referring, however, to actions outside the frame. It is a question of literary imagination, following in the footsteps of Daunais (1997), of the continuations of the theme represented, evoking scenes not represented but supposedly contained in the image, and suggesting another time, anterior or posterior, putting espectator of the painting and reader of the art critic facing two complementary cultural objects, in which one is the measure of the other.

KEYWORDS: art criticism; Gonzaga Duque; literature and painting
\end{abstract}

1 Pós-doutor em Estudos Literários pela UFMG e pela UFRJ, professor associado 4 da UFSM. Contato: andvieir@gmail.com. 


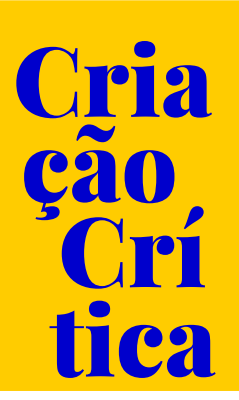

No contexto das múltiplas relações entre a pintura e a escrita, a crítica de arte ocupa lugar relevante. No caso de textos produzidos por escritores-críticos de arte, a questão adquire contornos mais específicos, mas não menos complexos. Se limitarmos ainda mais o espectro das reflexões sobre crítica de arte aos textos de escritores simbolistas do final do século XIX e início do XX, deparamos com um tipo de texto singularizado em sua forma e em suas funções. Para esta singularização da escrita, será preciso que o escritor-crítico de arte perceba o quadro como um objeto não apenas espacial, mas sobretudo temporal ao romper com os limites de sua materialidade em direção a outras artes, como a música e, sobretudo, a literatura.

"Rabiscador de crônicas", como ele mesmo se apresenta, Luiz Gonzaga Duque Estrada (1863-1911) foi o grande expoente do panorama cultural brasileiro dos últimos anos do século XIX à primeira década do século XX. Em suas críticas de arte, é possível encontrar uma riqueza de aspectos que dão conta, sobretudo, das produções artísticas brasileira e estrangeira de seu tempo. Seus textos exploram facetas da pintura e da literatura, a partir de seus cruzamentos e diálogos. Muitas de suas críticas se aproximam da crônica, seja pelo uso de diálogos com um interlocutor ficcional em sua visita a um Salão, seja na conversa irônica com seu leitor, retomando procedimentos já utilizados por Oscar Wilde em suas críticas. Em outros textos, por exemplo, a passante de Baudelaire pode servir de ponto de partida para suas reflexões enquanto perambula como um flâneur pelas alas de um museu: as observações sobre as obras são alternadas com as visões

d'uma esbelta senhora, encantadoramente cingida por um costume-tailleur cor de musgo [...] ao enviezar no lanço esquerdo, em frente ao nicho apanho-lhe o perfil, de relance. É claro. Tem a pupila negra. Negros the são os cabelos. (DUQUE, 1929, p. 115)

Não se trata aqui de focalizar a faceta do crítico de arte carioca como cronista, uma vez que esses aspectos que relacionam crítica e crônica em Gonzaga Duque já foram exaustiva e brilhantemente analisados por Vera Lins, sua maior especialista:

Gonzaga Duque molha a pena na palheta [...]; isto é, tem consciência de que cria uma linguagem, sua crítica se sabe um discurso, uma linguagem que pensa a si mesma enquanto pensa um quadro e vai-se fazendo também por imagens. Diz-se "um rabiscador de crônicas". (LINS, 2009, p. 63)

Meu intuito parte, ainda assim, da visão que Lins apresenta do crítico de arte como portador de uma consciência criadora de uma linguagem e de um discurso que reflete sobre si mesmo. Em sua busca por uma linguagem a meio caminho entre a ficção e a crítica, crítica narrativa em meio a descrições picturais, farei algumas reflexões acerca dos modos como o escritor e crítico de arte brasileiro descreve e narra de forma transficcional os quadros que comenta.

A ideia de que o quadro apresenta pontes entre a pintura e a literatura, entre a pintura e a música é frequente, segundo Isabelle Daunais (1997), entre os escritores-críticos de arte do final do século XIX e começo do XX. Começa a se impor a ideia de transposições de arte para escritores e críticos. Transpor consiste em fazer passar o lugar do quadro para outro lugar, agora acessível ao leitor, que é o lugar do texto. De maneira mais geral, a transposição da pintura ao texto se efetua por uma situação no espaço que faz eco ao cenário do quadro. Verdadeiro poeta da visão, o escritorcrítico simbolista adapta a materialidade de uma tela revestida de cores para melhor fazer a transposição do quadro pintado para o quadro (d)escrito. 


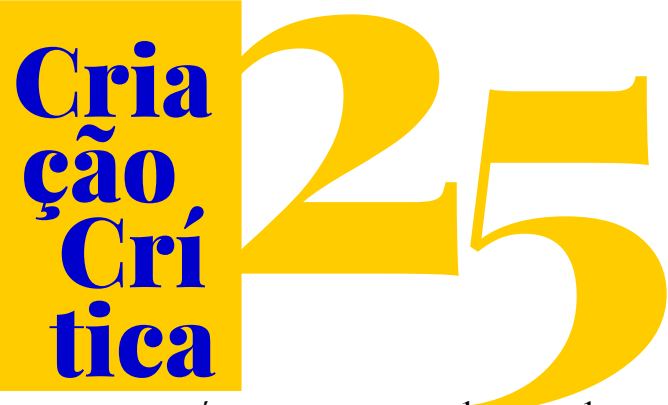

Se o tertium comparationis permanece ainda a tela da pintura, os critérios para a avaliação do quadro, através dos quais o crítico o observa, pertencem não mais somente à ordem do pictural, pois a obra de alguma forma ultrapassa seus domínios para a apropriação de vários outros. Em 1912, Apollinaire propunha a abordagem das obras sob o ângulo da transmutabilidade das formas de arte, sugerindo assim a ideia de paralelos e ultrapassagens. Avatar da écfrase clássica, a transposição de arte irá permear as relações entre o escritor e os quadros ao longo do século XIX, culminando nos textos de Huysmans, que passam a rivalizar com os quadros não mais descritos, mas doravante evocados. Desde os Salões de Diderot, no século XVIII, passando-se pelos textos sobre arte de Baudelaire, assiste-se, portanto, a uma transformação da tarefa do crítico de arte. Do mesmo modo, a prática descritiva que caracterizou o exercício de retórica da écfrase na Antiguidade dá lugar às evocações poéticas dos quadros por meio das transposições de arte. A obra de arte, neste sentido, deixa de ser objeto de descrição para os escritores-críticos e passa a ser objeto de tradução para a escrita.

O quadro passa a ser visto como objeto passível de ser traduzido: processo de transformação da expressão quando a obra de arte atinge os limites de sua própria materialidade, passagem de uma forma de arte a outra. Por um lado, observa Daunais, a crítica de arte do simbolismo comenta e analisa obras, artistas, correntes e formas, refletindo e descrevendo elementos que singularizam e dão unicidade à obra. Por outro, busca nessas mesmas obras aquilo que poderia pertencer a outras modalidades de expressão, aquilo que pode "ser transposto".

A crítica de arte do final do século XIX tenta reconciliar dois paradigmas: o positivista, da unicidade das obras [...] e o historicista, da comunicação entre as artes, a partir do qual é possível encontrar, para além das separações, os pontos de junção e os modos de ultrapassagem. Trata-se de descrever materialmente as obras, mas também de se interessar pelos valores da pintura enquanto forma de expressão modulável. Sem falarem diretamente de passagem entre diferentes formas de expressão, os escritores-críticos de arte na época da modernidade pictural comparam com frequência a pintura à poesia ou à música, reunindo-as como sinestesias. (DAUNAIS, 1997, p. 22, tradução nossa) ${ }^{2}$

Em muitas de suas críticas, Gonzaga Duque apela à literatura para melhor estabelecer e fundamentar sua visão dos quadros comentados. Na tradição da crítica de arte exercida por escritores como Huysmans, para quem os quadros de Gustave Moreau, por exemplo, apresentariam um estilo comparável ao dos irmãos Goncourt, Duque não hesita em associar a pintura de Félicien Rops à "diabólica lubricidade que possui algo da alucinação criadora de Edgard Poe e muito da funérea originalidade de Charles Baudelaire"(DUQUE, 1997, p. 21). Na revista Kosmos de fevereiro de 1908, Gonzaga Duque dedica seu texto à obra do pintor brasileiro Helios Seelinger, apelando novamente à literatura ao tratar dos quadros Salammbô e a lua e Salammbô e a cobra, inspirados na personagem do romance homônimo de Flaubert. Para além da referência direta ao tipo romanesco, Duque não se furta à comparação com a personagem emblemática de Huysmans, Des Esseintes, protagonista de À rebours (1884):

\footnotetext{
${ }^{2}$ Do original: "La critique d'art de la fin du XIX ${ }^{\text {ème }}$ siècle cherche en fait à réconcilier deux paradigmes: celui, positiviste, de l'unicité des œuvres [...], et celui, historiciste, de la communication entre les arts dont il est possible de trouver, par-delà des séparations, les points de jonction et les modes de dépassement. Il s'agit de décrire matériellement les œuvres, mais aussi de s'intéresser aux valeurs de la peinture en tant que forme d'expression modulable. Sans directement parler de passage entre les différentes formes d'expression, les écrivains critiques d'art à l'époque de la modernité picturale comparent souvent la peinture à la poésie ou à la musique, qu’ils réunissent comme en des synesthésies."
} 


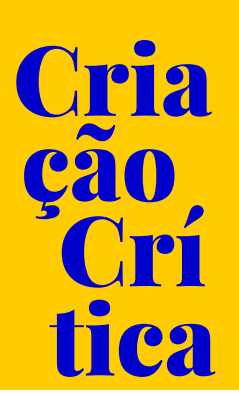

visto como uma linguagem capaz de mudar de forma. Cabe ao escritor encontrar esses "lugares de travessia". Também caberá ao escritor ver no quadro seus "momentos" e suas "sequências", ou seja, "de que maneira um objeto temporal poderia de uma só vez expressar o tempo e se expressar no tempo" (DAUNAIS, 1997, p. 24, tradução nossa) ${ }^{4}$. Trata-se então de ver o quadro em suas sequências e não mais vê-lo apenas como objeto espacial, mas antes como objeto temporal, o que inverteria as noções previstas por Lessing sobre artes do tempo (poesia) e artes do espaço (pintura, arquitetura, escultura).

Richard Saint-Gelais apela para o conceito de transficcionalidade para definir o momento em que elementos fictícios são retomados em mais de um texto:

Por "transficcionalidade" entendo o fenômeno através do qual pelo menos dois textos, de um mesmo autor ou não, se referem conjuntamente a uma mesma ficção, seja pela retomada de personagens, prolongamento de uma intriga prévia ou divisão do universo ficcional. (SAINT-GELAIS, 2011, p. 7, tradução nossa) ${ }^{5}$

Indissociável da ideia de travessia de fronteiras, a transficcionalidade opera a partir da possibilidade de expansão da ficção, seja em forma de continuações (sequels), seja em forma de narrativas anteriores (prequels) à ficção apresentada. Esta capacidade de a ficção transcender os limites do texto que a instaurou é analisada por Saint-Gelais em termos de relações entre obras literárias, mas podemos pensá-la no âmbito de críticas de arte que ficcionalizam a pintura, não apenas descrevendo o quadro concomitante à imagem, mas narrando o que viria antes ou depois do momento representado.

Ainda segundo Saint-Gelais (2011), a relação transficcional mais simples consiste em propor uma expansão para uma ficção já existente por meio de uma transficção que a prolonga no plano temporal ou, mais amplamente, no plano diegético. Entretanto, para que se possa ir além da imagem do quadro, é necessário romper com a noção de unicidade da pintura, noção positivista que vê a obra de arte como artefato acabado e totalizante, fechado em si mesmo. Ir além dos limites da imagem seria, portanto, perceber o quadro como linguagem aberta a correspondências, traduções e transposições entre as diversas artes.

Dar um prolongamento a uma narrativa é questionar os limites sobre os quais se
fixava a obra original. Tal gesto não saberia ser inocente em uma cultura que
funda sua concepção de obra como totalidade autônoma sobre a ideia de
fechamento, possuindo uma "forma" determinada, instaurando seu próprio
"código" e apresentando uma "rede de sentidos" específica. (SAINT-GELAIS,
2011, p. 71, tradução nossa) ${ }^{6}$

Por outro lado, a atividade crítica parte sempre de um olhar que transfigura a imagem em palavra. Na crítica de arte de escritores simbolistas, percebe-se o que Jean Starobinski qualifica como a busca de uma palavra poética que procura transpor a aparência visível em uma nova essência, uma vez

\footnotetext{
${ }^{4}$ Do original: "comme un objet temporel, à la fois exprimant du temps et s'exprimant dans du temps".

${ }^{5}$ Do original: "Par 'transfictionnalité', je comprends le phénomène par lequel au moins deux textes, du même auteur ou non, se rapportent conjointement à une même fiction, que ce soit par reprise de personnages, prolongements d'une intrigue préalable ou partage d'univers fictionnel".

${ }^{6}$ Do original: "Donner à un récit un prolongement, c'est remettre en question les limites que se fixait l'œuvre originale. Un tel geste ne saurait être innocent dans une culture qui fonde sur l'idée de clôture sa conception de l'œuvre comme totalité autonome, possédant une 'forme' déterminée, instaurant son propre 'code' et déployant un 'réseau de sens' spécifique".
} 


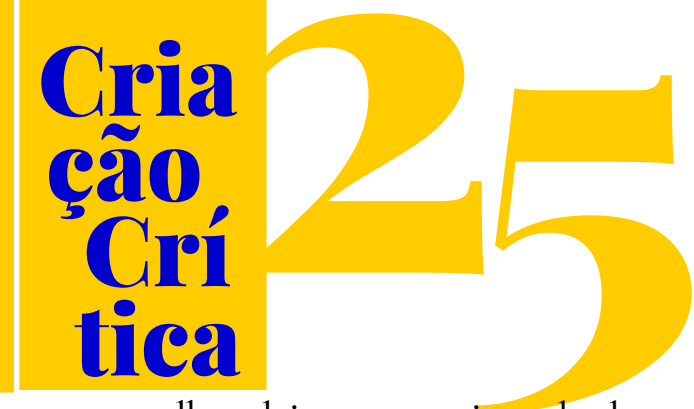

que falar, nomear as coisas tende a prolongar a obra preservando o que o olhar deixa sempre inacabado ou em estado precário. Assim, para os escritores, e também para os pintores, "a aventura se prolonga para além da primeira visão, mesmo se o desejo insatisfeito deva, mais tarde, após ter perdido o contato do sensivel, nos levar de volta" [a essa primeira visão] (STAROBINSKI, 1961, p. 17, tradução nossa).7

Ao escrever uma crítica sobre o quadro Descanso do modelo, pintado em 1882 pelo paulista José Ferraz de Almeida Júnior (1850-1899), Gonzaga Duque assim descreve a obra:

É um atelier de pintura. O interior é quente e banhado por uma luz fraca e igual. Num fundo de parede brilham duas faianças, uma moldura de quadro, o ferro agudo de uma lança. O pintor - um mestre, de longas barbas louras, corado, simpático, com a cabeça toucada por um barrete de veludo cor de vinho - acaba de descansar a palheta, acende o cigarro e, durante esse lapso de tempo perdido, o modelo - uma rapariga morena, preludia ao piano uma música.

- Muito bem! Muito bem!

Dize-lhe o mestre e bate palmas, a sorrir, com o cigarro entre os dentes. Ela pára, agradece-lhe com uma risadinha fresca e maliciosa os elogios. (DUQUE, 1995, p. 183-184)

Neste fragmento, podemos perceber certos aspectos que remetem a algumas das questões supracitadas. Em primeiro lugar, é interessante observar que o crítico de arte parece ter encontrado aquele lugar/momento que o quadro oferece para a entrada em sua materialidade. Entre o instante em que o pintor acaba de descansar sua palheta e o final da música tocada ao piano pela modelo, a cena é narrativizada. Cena anterior, narrativa do que teria ocorrido até o momento em que o instante é representado pela pintura. O crítico imagina mesmo o que teria dito o pintor, não hesitando em lhe dar voz, em discurso direto: “- Muito bem! Muito bem!". Predomina o tempo verbal das descrições picturais, o presente do indicativo, um presente que parece querer justamente demarcar o tempo do quadro, tempo de uma arte do espaço, diverso do tempo de uma narrativa literária tout court, na qual imperam os tempos dos passados perfeito e imperfeito.

Figura 1: José Ferraz de Almeida Júnior, Descanso do modelo (1882), detalhe

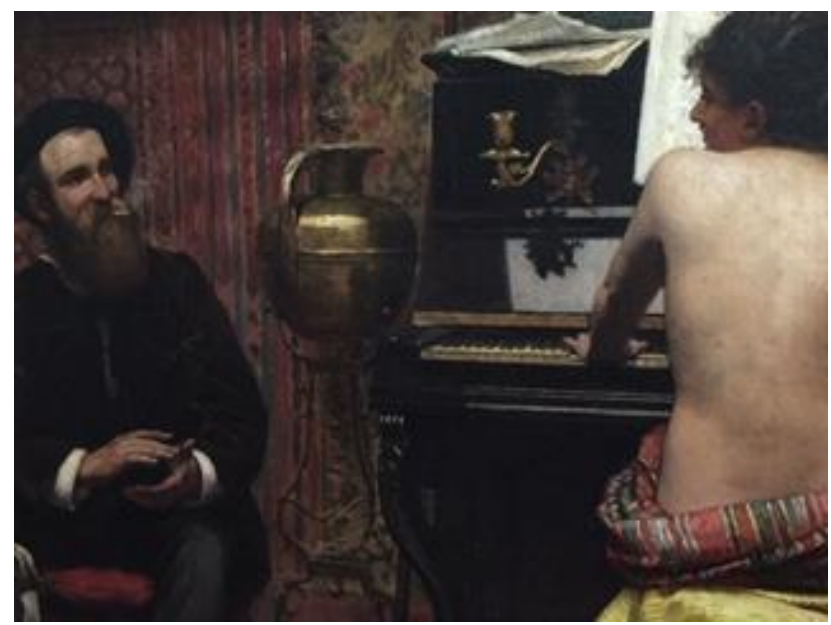

Foto do Museu Nacional de Belas Artes do Rio de Janeiro.

\footnotetext{
${ }^{7}$ Do original: "l'aventure se prolonge au-delà de la première vue, même si le désir insatisfait doit plus tard, après avoir perdu le contact du sensible, nous y ramener".
} 


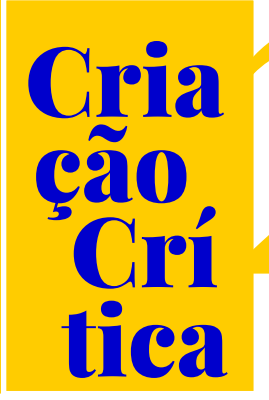

los com o uso dos meios que são próprios à literatura: os signos verbais. Em suma, a pintura descrita não constitui uma pintura, mas faz uma alusão/referência/evocação ao quadro descrito por intermédio das palavras, como se fosse uma pintura mas na materialidade da escrita e com os meios de que dispõe ao imitar os procedimentos pictóricos e adaptá-los ao sistema verbal.

A segunda direção, ao contrário da primeira, apresenta

uma leitura que consiste em encontrar na imagem aquilo que the pertence, mas que seria melhor revelado pela escritura [e] permite a tradução da obra em um terreno propriamente da escrita. Ora, essa leitura do quadro, que assegura a passagem entre as duas artes, a do pintor e a do escritor, possibilita uma redefinição da presença do pictural na literatura do século XIX: se os escritores estudaram de tal forma a imagem, isso se deu pelo que ela contém de narrativo. Dito de outra forma, os escritores teriam ido buscar na pintura não a pintura, mas a literatura. (DAUNAIS, 1997, p. 29, tradução nossa) ${ }^{8}$

Para que possamos melhor entender e aceitar premissas como essa, é preciso ter em mente que até o início do século XX, a pintura, seguindo a tradição clássica, mas também em sua transição para a modernidade durante o século XIX, só pode ser concebida em termos de representação. Mesmo os artistas de vanguarda não conseguem se afastar de um modelo de pintura que represente alguma narrativa, seja ela religiosa, mítica, histórica, de gênero ou de costumes. Pelo menos até o advento do Impressionismo, a pintura é indissociável da narração alegórica, histórica ou mística segundo uma perspectiva literária. Delacroix, consagrado por suas pinturas descritivo-narrativas, será o primeiro a integrar o alegórico à realidade histórica de seu tempo, como o demonstra um de seus quadros mais emblemáticos, A liberdade guiando o povo (1830). Em busca daquilo que o quadro contém de literariamente temporal, a crítica de arte parte de um aspecto tido, portanto, como inerente à pintura, seu caráter narrativo, para afirmar a correspondência artística entre uma arte do tempo (a literatura) e uma arte do espaço (a pintura), conforme a classificação de Lessing.

Visto como objeto espacial que pode ser transmutado em objeto temporal, o quadro se prestaria a descrições narrativas para frente, para trás ou concomitantes ao referente primeiro: sua imagem representada. Narrativas anteriores, prequels, seriam as mais utilizadas por críticos como Gonzaga Duque, no Brasil. Construído em torno do referente, o texto narrado é elaborado a partir do assunto da tela, remetendo, no entanto, a ações exteriores ao quadro. Trata-se de imaginar literariamente as continuações do tema representado, evocando cenas não representadas, mas supostamente contidas na imagem (DAUNAIS, 1997, p. 25), e sugerindo um outro tempo, anterior ou posterior.

\footnotetext{
${ }^{8}$ Do original: "une lecture qui consiste à trouver dans l'image ce qui lui appartient mais que l'écriture révèle davantage permet de traduire l'œuvre sur un terrain proprement scriptural. Or cette lecture du tableau, qui assure le passage entre les deux arts, celui du peintre et celui de l'écrivain, n'est pas sans s'ouvrir sur une possible redéfinition de la présence du pictural dans la littérature au XIXème siècle: si les écrivains ont tant étudié l'image, ce serait pour ce qu'elle contient de narratif. Autrement dit, les écrivains seraient allés chercher dans la peinture non pas la peinture, mais la littérature".
} 


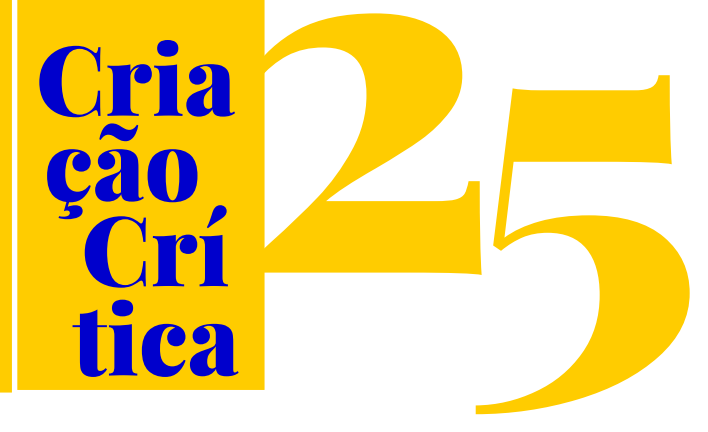

Figura 3: Mariano Barbasán Lagueruela, Cataplum (1907)

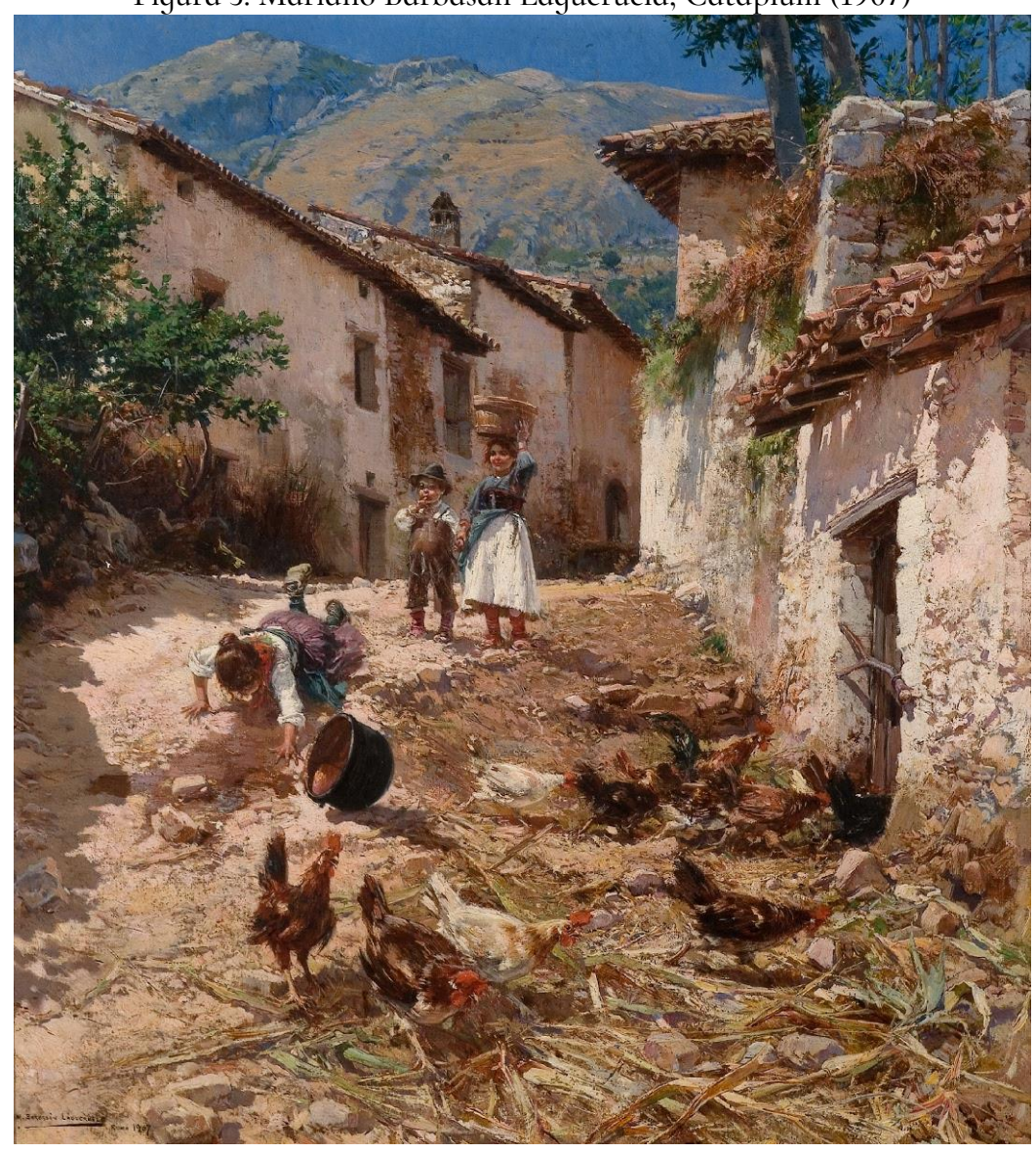

Disponível em: <artsandculture.google.com> Acesso em: 04 maio 2019

O quadro do pintor espanhol Mariano Barbasán Lagueruela (1864-1924), onomatopeicamente denominado Cataplum, de 1907, serve de motivo para uma crítica de Gonzaga Duque na qual é possível perceber o uso que o autor de $A$ arte brasileira faz dos procedimentos acima apontados:

É uma ruasita de aldeia, em Itália, creio. Muito lixo, muita galinha e muitos galos... o dia está lindo, um glorioso dia, [...] o sol vai quente, brune o céu, metaliza raras folhagens de raros arbustos, lasca em vibrações a pedra e a caliça do casario reúno, acaçapado e caturra. Uma petiza, que já floreja em moçoila, vem com uma caçarola [a] caminho de casa; mas, como é traquinas ou descuidada, não atende por onde pisa, e, num dado momento, cataplum... bate de ventas na esterqueira da ruasita. E esperneia, escabuja, berra, desesperada com a queda e mais danada com a perda das papas, o que lhe há de custar, conjeturamos, uma roda viva de valentes petelecos se não for de rudes tabicadas. E os irmãozinhos, que a seguiam, sem saberem o que fazer, ficam pasmados a "ver a cena", enquanto galinhas, galos e frangotes alarmados com o berreiro, se escamujam por todos os cantos, em cacarejos desesperados. 


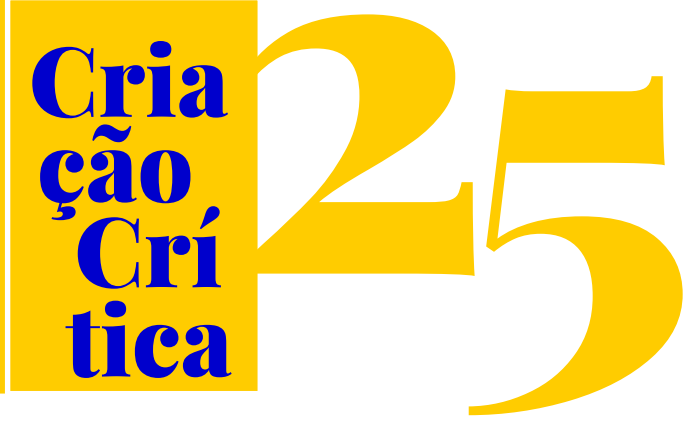

Aí tem, como me foi possível traduzir ${ }^{9}$, o que é o Cataplum do Sr. Barbasán Lagueruela, um quadrinho que pouco mais passa de um palmo. (DUQUE, 1929, p. 155)

Gonzaga Duque transficcionaliza a imagem do quadro que, por seu próprio assunto, conta uma história. Após situar a narrativa pela descrição da paisagem pitoresca, o crítico, assumindo a função de um narrador na primeira pessoa do singular (creio) e a seguir na primeira do plural (conjeturamos), apresenta ao leitor/espectador a sua visão do quadro. Mais precisamente, aquilo que seu olhar capturou ao vislumbrar a tela: captura, vislumbre de uma história que culmina com a queda da menina, momento isolado pelo pintor. No intervalo temporal, em sua dimensão lacunar, entre o instante em que as três crianças surgem do fundo do quadro, caminhando, a mais velha à frente, e o momento da queda, nasce a ficção. O crítico-narrador, aquele que parece observar todo o desenrolar da ação a partir de sua janela, no ponto onde o espectador é colocado, ainda conjectura prolepticamente sobre o castigo que a personagem poderá vir a sofrer pelo acidente (tabicadas e petelecos). Transficcionalizando a pintura, Gonzaga Duque distingue-se de seus antecessores e contemporâneos, indo além dos processos de écfrase e de transposição de arte ao refletir sobre novas possibilidades do fazer crítico.

Seguindo os passos de Merleau-Ponty, para quem o sentido que se dá às obras nasce diretamente das mesmas, uma vez que é a própria obra que abre o campo de onde ela provém, sob outra luz, metamorfoseando-se e tornando-se sequência, "as reintrepretações intermináveis de que ela é legitimamente suscetível não a transformam senão nela mesma" (1984, p. 102). A pintura deu a si própria o que Merleau-Ponty denomina de movimento sem deslocamento, por vibração ou irradiação, algo necessário tendo em vista tratar-se de uma arte do espaço, realizando-se na tela ou no papel. Mas a tela imóvel também poderia sugerir uma transição, uma mudança de lugar, um movimento que ela mesma não contém em si:

O quadro forneceria a meus olhos pouco mais ou menos aquilo que os movimentos reais lhe fornecem: vistas instantâneas em série, convenientemente baralhadas, com, se se trata de um vivente, atitudes instáveis em suspenso entre um antes e um depois, em suma, os exteriores da mudança de lugar que o espectador leria no seu rastro. (MERLEAU-PONTY, 1984, p. 106-107)

Entre o antes e o depois da queda da menina no quadro de Barbasán Lagueruela, Gonzaga Duque captura o que a imagem fornece subrepticiamente, como se a retina precisasse de um antes e de um depois da imagem que, ainda que imóvel, sugere o movimento para frente e para trás, pois o quadro apresenta o movimento: movimento que não se move. Conforme Merleau-Ponty observou, segundo Rodin, o que proporciona o movimento, ou sua ilusão em nossa retina,

é uma imagem em que os braços, as pernas, o tronco, a cabeça são tomados cada um em outro instante, uma imagem que, portanto, figura o corpo numa atitude que ele não teve em nenhum momento, e impõe entre suas partes ligações fictícias, como se esse enfrentamento de incompossíveis pudesse, e só ele, fazer surgir no bronze e na tela a transição e a duração. (MERLEAU-PONTY, 1984, p. 107)

\footnotetext{
${ }^{9}$ Grifo nosso.
} 
